\title{
Mild cognitive impairment in older adults: the role of cognitive reserve and resilience
}

\author{
Bess Yin-Hung Lam \\ Hong Kong Polytechnic University \\ Daniel W.L. Lai \\ Hong Kong Polytechnic University \\ Jessica Li \\ Hong Kong Polytechnic University \\ Zhi Zou \\ Sun Yat-sen University Sixth Affiliated Hospital \\ Chetwyn C. H. Chan ( $\nabla$ chetwyn.chan@polyu.edu.hk) \\ https://orcid.org/0000-0003-0307-6337
}

\section{Research article}

Keywords: mild cognitive impairment, resilience, cognitive reserve, age-related neurodegeneration

Posted Date: June 5th, 2020

DOI: https://doi.org/10.21203/rs.3.rs-29135/v1

License: (c) This work is licensed under a Creative Commons Attribution 4.0 International License. Read Full License 


\section{Abstract \\ Background}

Positive ageing amid of age-related neurodegeneration is a global challenge. The present study examined whether psychological resilience can be a protective factor among older adults.

\section{Methods}

The participants were 233 community-dwelling older individuals with or without mild cognitive impairment $(\mathrm{MCl})$. They completed testing on resilience and the cognitive reserve proxies. Hierarchical logistic regression was conducted to test the hypotheses of the present study.

\section{Results}

After controlling for age and the cognitive reserve proxies, resilience $(b=-0.38)$ and resilience $\times$ visuospatial function significantly predicted $\mathrm{MCl}$ group membership ( $\mathrm{ps}<0.05$ ). There are two new findings. First, higher level of resilience in addition to the conventional cognitive reserve proxies predicted lower $\mathrm{MCl}$ risks. Second, $\mathrm{MCl}$ participants with higher level of resilience had significantly higher visuospatial ability than their lower level counterparts.

\section{Conclusions}

These findings raise the question of whether resilience should be considered as a cognitive reserve proxy. It also calls for future research to enhance the level of resilience in older adults for healthy ageing.

\section{Background}

According to World Health Organization, 16\% of the world population will reach the age of 65 years or older by 2050 [1]. Age-related neurodegenerative diseases (e.g., dementia) has imposed an enormous burden on the health care system [2]. Promotion of healthy ageing is a key agenda embraced in the society. Better understanding of the protecting factors which slow down degeneration might help designing interventions for promoting heathy ageing in older adults. Cognitive reserve is a common construct theorizing neurodegeneration in older adults [3-6]. It is the ability to actively make flexible and efficient use of brain reserve that is available in the performance of tasks [5].

Proxies of cognitive reserve include education, intelligence, memory, visuospatial function and literacy [3, 7-11]. Among these variables, visuospatial ability has been recently revealed to be more sensitive to age-related decline when compared to other cognitive abilities such as verbal component of working memory $[12,13]$. For instance, Suri et al. reported that visuospatial memory was significantly related to the resting state hippocampal-parietal and motor-parietal interactions in older adults [14]. As the atrophy in the hippocampal region is hallmark of Alzheimer's Disease [15-17], investigating the decline in visuospatial function and its relationships with other variables would help build a more robust model of cognitive reserve for neuroprotection in older adults $[3,18,19]$.

Besides visuospatial function, another construct which is the focus of this study is psychological resilience. Classic diagnostic criteria of mild cognitive impairment $(\mathrm{MCl})$ appear to bias towards cognition such as the adoption of self-report cognitive decline and objective cognitive measure [20-22]. This prompts the question, would psychosocial construct such as resilience presently not included as a criterion for $\mathrm{MCl}$ as well as cognitive reserve is protective of $\mathrm{MCl}$ ? Recent studies reported that higher level of resilience related to reduced mortality risk in older adults [23-28], better self-perceptions of ageing [24, 27, 29], and improved quality of life in older adults [23-25, 28, 29]. Resilience 
has been rephrased as "the process of adapting well in the face of adversity, trauma, tragedy, threats, or significant sources of stress, or 'bouncing back' from difficult experiences" [30]. This definition has been supported by the evidence that those with high resilience were found to more readily adapt to chronic illness and traumatic disabilities than those with low resilience [31]. The Connor-Davidson Resilience scale (CD-RISC) is a measure of resilience relevant for use in a variety of individuals including older adults [29, 32]. Resilience has an age-related characteristic as previous studies revealed that older adults had significantly higher level of resilience than younger adults especially with respect to emotional regulation and problem solving [26, 33, 34]. As suggested by Gooding et al. [26], the higher level of resilience in older adults might be due to the development of more effective coping strategies when compared to the younger adults. Nevertheless, these results indicated the differential psychological processes underlying resilience across the lifespan. Given that individuals diagnosed as $\mathrm{MCl}$ could have experienced feeling of incompetence, adversity, and trauma, resilience may play a protective role by deploying the compensatory strategies to boost cognitive abilities and prevent them from developing pathological symptoms.

Compensation due to functional decline is a common phenomenon in older adults, and the posterior-anterior shift (or called PASA) occurs in combating age-related cognitive decline. According to PASA, physiologically, compensatory mechanism has been supported by the ability in older adults on recruiting new brain networks for maintaining the originally declined performances [35, 36]. Yet, visuospatial function, resilience, and their relationships with cognitive reserve in $\mathrm{MCl}$ have not been studied. The present study was aimed to investigate how resilience and visuospatial function, in the context of cognitive reserve, can modulate age-related neurodegeneration. It was hypothesized that higher resilience would predict lower risks of $\mathrm{MCl}$ in community-dwelling older adults. Resilience would have comparable contributions to the lower risks as the three cognitive reserve proxies - years of education, intelligence and visuospatial function. In addition, it was hypothesized that there would be interaction effect of visuospatial function and resilience in predicting $\mathrm{MCl}$. Findings of this study will enrich the construct of cognitive reserve in defining neurodegeneration as well as the potential of resilience to be a factor for enhancing positive ageing.

\section{Materials And Method}

\section{Participants}

Invitation leaflets were delivered to older adult members of different community organizations with more than 2000 members having a variety of demographic background (e.g., living in different districts in the city) for subject recruitment. Two hundred and thirty-three community-dwelling older adults were recruited from these community organizations on a voluntary basis. Their mean age was 64.9 years (S.D. $=3.8$ years; range $=60$ to 79 years; $32.6 \%$ males). The average years of education were 13.0 (S.D. $=4.1$ ). The age and years of education were significantly different between the healthy and $\mathrm{MCl}$ participants ( $\mathrm{ps}<0.05$ ) (Table 1$)$. All participants were with normal or corrected-tonormal visual and auditory function. The participants with a history of cognitive impairments (e.g., dementia, head injury, and cerebrovascular disease) and depression were excluded from the study.

\section{"Insert Table 1 here"}

\section{Data Collection Procedures}

Age, sex, years of education, and independence in daily activities - personal hygiene and car, locomotion in the home, meal preparation, running errands, housework and finances of the participants were obtained by means of intake interview. Hong Kong version of the Montreal Cognitive Assessment (MoCA-HK) was administered to each participant for assessing their visuospatial and executive functions, naming, attention, language, abstraction, delayed recall, and orientation functions [37]. The diagnostic criteria for participants classified as the $\mathrm{MCl}$ group (specifically for Chinese individuals with seven or more years of education) included: 1) MoCA score of 24 or below [38]; 2) self- 
reported independence in daily living activities; and 3) self-reported cognitive decline [20-22]. Those who scored 25 or higher on MoCA-HK were classified into the healthy control group. These diagnostic criteria were adopted from a recent study by the author [20] and other previous studies by other researchers $[21,39,40]$.

All participants completed measures for assessing their cognitive reserve -intelligence and executive function, short-term memory and visuospatial ability, and the CD-RISC for resilience function. All participants were able to understand the assessments administered in the present study.

Intelligence and executive function were assessed by Test of Nonverbal Intelligence (TONI-3) which taps on participant's aptitude, intelligence, abstract reasoning, and problem solving in a language free format [41]. Short-term memory was measured by the immediate story recall subscale of Rivermead Behavioural Memory Test-Third Edition (RBMT-3)- Chinese version [42]. This RBMT subscale taps on participants' short term memory and the Chinese version has been validated. Visuospatial ability was measured by Judgment of Line Orientation (JLO) [43]. In this test, participant was asked to discriminate the direction of lines in 30 items. In each item, participants saw a pair of lines on a page and was to estimate the inclination of the pair of lines by using another page with 11 lines (numbered from 1 to 11 ) as a reference. Each line is separated by an angle of 18 degrees. The CD-RISC is a 10-item self-report scale tapping on participant's ability to thrive in the face of adversity, adaptability when coping with change, social problem solving skills, humor in the face of stress [44]. It showed good reliability in the present study (internal consistency= 0.90). Previous studies also reported CD-RISC had one of the best psychometric ratings in adults [45]. Based on the CD-RISC median score of 28, participants in this study were further classified into the lower resilience (<= 28 ) and higher resilience groups (> 28) for examining possible moderation effect of resilience on the diagnosis of $\mathrm{MCl}$ (see Figure 1 ).

"Insert Figure 1 here"

\section{Statistical Analysis}

Pearson's correlation was used to examine the relationships among the major variables at the total and subgroup levels. Independent t-test was conducted to compare the differences in the major variables between the higher and lower resilience among the participants. Hierarchical logistic regression was conducted for predicting participants' group members (MCl versus healthy) by the cognitive reserve proxies and resilience variables. The four blocks in the model were: age in block 1; years of education in block 2 with scores of TONI-3, RBMTstory recall and JLO as the covariates; score of CD-RISC as the covariate in block 3; the interaction effects in the preliminary model as the covariate in block 4. Significant moderating factor(s) was tested between the higher versus lower resilient subgroups (based on median split CD-RISC scores). All analyses were conducted using SPSS 25.0 and statistical significance were set at $p=.05$ (2- tailed) [46].

\section{Results}

Among the total sample, 35 participants (15.0\%) fulfilled the diagnostic criteria for being classified in the MCI group. The other 198 participants (85.0\%) were classified in the healthy group. Mean ages for the healthy and $\mathrm{MCl}$ groups were 64.6 (S.D.= 3.7 years) and 66.7 years (S.D. 3.9 years), respectively. The average years of education for the two groups were 13.4 (S.D.= 4.0 years) and 10.4 (S.D.= 4.2 years), respectively (Table 1$)$. With the entire sample $(\mathrm{N}=233)$, age of participants was significantly and negatively correlated with all variables of interest except scores of CD-RISC and RBMT-story recall ( $r s=-0.17$ to $-0.29, \mathrm{ps}<=0.01$ ). Significant and positive associations were found among the four cognitive reserve proxies (years of education, TONI-3 score, RBMT- story recall score and JLO score) and participants' MoCA score ( $r s=0.26$ to $0.41, \mathrm{ps}<=0.001$ ). Moreover, scores of CD-RISC were positively and significantly related to those of TONI-3, JLO, and MoCA (rs $=0.16$ to $0.18, \mathrm{ps}<=0.050$ ) (Table 2$)$.

"Insert Table 2 here"

Among the $\mathrm{MCl}$ participants, score of resilience was significantly correlated with JLO score ( $r=0.56)$, TONI-3 score ( $r=0.43)$, and MoCA score $(r=0.35)$ (Table 2). These contrast with the healthy participants of which all correlations between resilience and other three cognitive function variables were not significant ( $\mathrm{ps}<0.05$ ). To further explore the resilience $\times$ JLO interaction effect, median score 28 of CD-RISC was used to divided the $\mathrm{MCl}$ and healthy groups into higher and lower resilient subgroups (Figure 1). Among the $\mathrm{MCl}$ participants, those with higher

Page $4 / 14$ 
resilience scores performed significantly better on the JLO than those with lower resilience score $(t(33)=-2.99, p=.005)$. No significant differences in terms of MoCA, TONI-3, RBMT-story recall scores were revealed between the MCl higher and lower resilience subgroups. In contrast, there were no significant JLO score difference between the two healthy subgroups $(t(196)=-1.36, p=.174)$. MoCA, TONI-3, RBMTstory recall scores also did not significantly differ between these two subgroups ( $p s>0.05$ ). By comparing the four subgroups (healthy participants with high or low resilience scores, and $\mathrm{MCl}$ participants with high or low resilience scores), the two subgroups of healthy participants had higher MoCA scores than both $\mathrm{MCl}$ subgroups respectively ( $\mathrm{ps}<0.001)$. As for the JLO performance, two healthy subgroups and the $\mathrm{MCl}$ participants with high resilience scores had higher scores than the $\mathrm{MCl}$ participants with low resilience scores $(\mathrm{ps}<0.01)$. Moreover, significant positive correlation was found for JLO and MOCA score in the higher resilient participants but not the lower resilient ones in both pairs of subgroups (MCl: higher: $r=0.56, p=.026$; lower: $r=0.08, p=.742$ ) (Healthy: higher: $r=0.27, p=.005 ;$ lower: $r=0.14, p=$ .193).

\section{Logistic regression analyses}

Significant associations were found among age, years of education, RBMT- story recall score, TONI-3 score, JLO (Judgment of Line Orientation) score, resilience score, and resilience $\times \operatorname{JLO}(X 2(7)=41.46, p=<.001)$. The overall logistic regression equation in predicting participants' $\mathrm{MCl}$ membership was $\left(p=1 /\left(1+\exp \left[-\left(b 1 * a g e+b 2 *\right.\right.\right.\right.$ years of education $+b 3^{*}$ TONI-3 + b4*JLO + b5*RBMT-story recall + b6*resilience $+b 7 *$ resilience $x$ JLO + b0)]. Significant predictors of participants' $\mathrm{MCl}$ memberships in the overall regression model after the control of age $(b 1=0.05$, s.e. $=0.06, p=.356, O R=1.05)$ were: years of education $(p=.035, O R=0.87)$, TONI-3 score $(p=.004, O R=0.91)$, JLO score $(p=.051, O R=0.64)$, RBMT- story recall score $(p=.045, O R=0.86)$, resilience score $(p=.028, O R=0.68)$ and resilience $\times J L O(p=$ $.030, \mathrm{OR}=1.02)$ (Table 3$)$. In block 1 , age significantly predicted $\mathrm{MCl}$ membership $(p=.004)$ accounting for $6.2 \%$ of the total variance. The years of education $(p=0.006)$ and TONI-3 $(p=0.015)$ in block 2 were significant predictors explaining an additional $19.7 \%$ of the total variance. No significant gains in the prediction was observed in the block 3 . The significant variables in blocks 2 and 3 together with the score of resilience $(p=.028)$, resilience $\times \operatorname{JLO}(p=.030)$, and RBMT- story recall $(p=0.045)$ entered into block 4 accounted for a total of variance of $29.5 \%$ for classifying $\mathrm{MCl}$ membership. The total model yielded an accuracy of $86.2 \%$ predicting $\mathrm{MCl}$ versus non-MCl memberships.

"Insert Table 3 here"

\section{Discussion}

The present study examined psychological resilience together with the conventional cognitive reserve measured as protective factors of neurodegeneration in a sample of community-dwelling older individuals. Major findings are that higher level of resilience and cognitive reserve significantly predicted lower risks of $\mathrm{MCl}$. More importantly, resilience appears to be a stronger predictor of $\mathrm{MCl}$ after controlling for the age and cognitive reserve variables. These findings suggest that in addition to conventional cognitive reserve, resilience may play an equally important role in lowering the risk of $\mathrm{MCl}$ in older adults. Resilience was found to correlate moderately with all the cognitive functions except short term memory function specifically in $\mathrm{MCl}$ older adults. Among them, the strongest relationship was with visuospatial function which was measured by JLO $(r=0.56, p<0.001)$ in the present study. The results support the notion that resilience could be a facilitating factor enhancing higher cognitive functions in the participants with $\mathrm{MCl}$. It is plausible that such enhancement would have been the effect of increase in motivation and deployment of compensatory strategies amid the neurodegeneration experienced by these individuals.

\section{Resilience as the neuroprotective factor of $\mathrm{MCl}$}

Resilience has been revealed to play a role in positive ageing [47]. Behaviorally, older adults with higher resilience were more likely to be independent in activities of daily living [48], and have better adaptive coping styles [49], better health outcomes and mental well-being [50, 51], as well as reduced cognitive failures [52]. Different from previous studies focusing on conventional cognitive reserve proxies [3, 7-11], findings of this study indicate that resilience apart from the conventional cognitive reserve proxies were associated with lower risks for $\mathrm{MCl}$. An increase in one unit of the cognitive reserve proxies would decrease the odds of $\mathrm{MCl}$ by 0.64 to 0.91 suggesting that increased levels of cognitive reserve proxies reduce the risk of $\mathrm{MCl}$. More importantly, there would be a decrease of the odds of $\mathrm{MCl}$ by 0.68 for a point increase of resilience indicating that the more resilient the less chance of $\mathrm{MCl}$. Moreover, the combined variances of the $\mathrm{MCl}$ diagnosis explained by the cognitive reserve proxies and resilience were $19.9 \%$. The findings support the notion that resilience could be a protective factor enhancing higher cognitive functions in the individuals with $\mathrm{MCl}$. As resilience is related to general flexible, compensational and adaptive coping ability in the face of adversity, the "declining" brain reserve would have been regarded as the adversity in older adults and hence they incline to 
efficiently and flexibly adapt to the task demands [35, 36]. Besides, resilience has been reported to exert a significant top-down effect for influencing one's flexibility in behaviors. Such effect therefore would have been general rather than specific for benefiting older adults particularly those experiencing an overall decline in cognitive functions. Our proposition is supported by previous studies on resilience in healthy ageing. For instance, Genet and Siemer stipulated that cognitive flexibility and flexible affective processing were associated only with trait resilience but not other trait measures including extraversion and neuroticism [53]. Moreover, it was found that resilience significantly contributed to the critical proximal factors such as work and social engagement which are important for healthy ageing in older person with multiple sclerosis [54]. Taken these altogether, the enhancement in cognitive functions induced by resilience may potentially be due to the effect of increase in motivation and deployment of compensatory strategies amid the neurodegeneration in these individuals.

\section{Resilience and cognitive functions in $\mathrm{MCl}$}

Resilience moderating the visuospatial ability among the $\mathrm{MCl}$ participants is a new finding. The results suggest that the $\mathrm{MCl}$ participants who had higher level of resilience had significantly better visuospatial ability than those with lower level of resilience. Such differences were not observed among the healthy older participants. Besides visuospatial function, in both the $\mathrm{MCl}$ and healthy groups, participants with higher level of resilience also had significantly higher intelligence, executive function and other cognitive functions. The results on healthy controls are consistent with those reported in previous studies. For instance, Lamond et al. [52] reported that resilience had a positive impact on the cognitive functions which included more self-rated successful ageing and fewer cognitive complaints in a group of healthy older adults. No study however has been reported in individuals with $\mathrm{MCl}$. However, why visuospatial ability was the only cognitive function that was impaired in the $\mathrm{MCl}$ participants with the present data. In this study, visuospatial function was measured with JLO (judgement of line orientation). The test items of JLO are characterized with the fine-grain spatial discrimination required in the participants. A participant was required to match the orientation of a pair of lines to a set of 11 lines with 18 degrees separated from each other. The extent of differences and similarities between the source and target were manipulated. The smallest differences in the angle can be as little as less than 18 degrees [43]. Making a correct response would need the participant to encode the orientation of the lines, holding the spatial information in visual working memory, and appraise the orientation of the pairs of lines for matching. The task demands as described herein would have been novel and more challenging to the $\mathrm{MCl}$ participants when compared with other cognitive measures which is in line with prior finding that visuospatial impairment might be an independent sign of $\mathrm{MCl}$ and other neurodegeneraitve diseases [51]. Lesions in the posterior parietal cortex that are unique to amnestic $\mathrm{MCl}$ individuals [55] match with the neural substrate that is associated with the poor performance on JLO [56]. The challenges posed by the JLO to the $\mathrm{MCl}$ participants could have been perceived as "adverse" and hence those with higher resilience would have responded in adaptive ways. The underlying mental strategies deployed and hence the underlying mechanisms for explaining the observed phenomena are beyond the scope of this study. Future research is needed to explore these two aspects. Taken all these findings together, the assessment and treatment planning for $\mathrm{MCl}$ individuals are suggested to take cognitive reserve and resilience into considerations.

Not only that the present research findings have theoretical implications, they can be translated to clinical strategies for enhancing neuroprotection in older adults with $\mathrm{MCl}$. Specifically, a few existing interventions found effective for improving the level of resilience in younger adults [57] and children [58] can be considered for adapting to address the characteristics and the needs of older adults. For instance, the Coherence Advantage Training is a program for building the capacity to recognize and self-regulate responses to stressors in both work and personal contexts for police officers in the United States [57]. The training program was revealed to effectively enhance the physiological and psychological recovery from stressors in the participants. This program includes learning what resilience is, practicing selfregulation of emotion, and integrating alternative cognitive strategies into daily life. Relevant to visuospatial function and older adults with $\mathrm{MCl}$ is to explain the processes underlying the decline in the function and how such decline would become a stressor in individual's daily life, such as recalling where objects are organized in a cupboard. Resilience training, strengthening the adaptation process, involves learning to accept the decline in one's ability to decode the relative positions of objects in the cupboard. Instead of indulging in the frustrating emotion, older adults learn the use of semantic method to register the objects and contextualize the objects for easier memory recall. Future study will employ evidence-based practice approach for adapting other resilience training programs for improving older adults' resilience which in turn decreases their risk of cognitive decline progressing into $\mathrm{MCl}$.

\section{Limitations and future directions}

The present findings revealed resilience as the significant protective factor of $\mathrm{MCl}$ in older adults. However, this study suffered from a number of limitations which should be addressed in future studies. First, the findings were based on cross-sectional data which did not take the temporal factor and it may influence the relationship between cognitive reserve, resilience and cognitive impairment. For instance, Netuveli et al. found that resilience was positively related to age [33]. Second, the present study only assessed four proxies of cognitive reserve. Future studies are suggested to take a broader perspective in understanding the cognitive reserve by investigating more proxies such as long-term memory. Third, since MoCA is to detect possible $\mathrm{MCl}$, future studies should also consider using a comprehensive neuropsychological battery 
to address the cognitive status of the participants. Last but not least, the present study only focused on cognitive reserve but not brain reserve. Future studies are suggested to investigate the interaction between cognitive reserve and brain reserve in the prediction of $\mathrm{MCl}$.

\section{Conclusions}

The present study examined the predictive effect of conventional cognitive reserve and psychological resilience on the risks of $\mathrm{MCl}$ in older adults. The present findings suggest that in addition to conventional cognitive reserve, higher level of resilience predicts less risk of $\mathrm{MCl}$ in older adults. Higher level of resilience enhances the visuospatial ability in the people with $\mathrm{MCl}$ and such effect is not observed in healthy controls. It is worthwhile to consider including resilience as part of the cognitive reserve for describing neurodegeneration in older adults. The present findings offer insight into exploring of the mechanism behind resilience as a modulating factor of early neurodegeneration as well as designing assessment and intervention for the $\mathrm{MCl}$ individuals.

\section{Abbreviations}

CD-RISC: The Connor-Davidson Resilience scale; JLO: Judgement of Line Orientation; MCI: Mild Cognitive Impairments; MoCA-HK: Hong Kong version of the Montreal Cognitive Assessment; PASA: posterior-anterior shift; TONI-3: Test of Nonverbal Intelligence; RMBT-3: Rivermead Behavioural Memory Test - Third Edition

\section{Declarations}

\section{Ethics approval and consent to participate}

Ethical approval was provided by the Research Committee at the affiliation of one of the authors. All procedures performed in this study involving human participants were in accordance with the ethical standards of the institutional and/or national research committee and with the 1964 Helsinki declaration and its later amendments or comparable ethical standards.

\section{Informed written consent form}

Participants' written informed consent was obtained.

\section{Consent for publication}

All authors have contributed to the work, agree with the presented findings, and that the work has not been published before nor is being considered for publication in another journal.

\section{Availability of data and material}

The data of the present study is available upon request.

\section{Funding}

Nil.

\section{Authors' contributions}

CC and DL conceived of the study, participated in its design and coordination and commented on the draft of this manuscript; $B L$, JL and ZZ helped with the data collection; and BL performed the statistical analysis and helped to draft the manuscript. All authors read and approved the final manuscript. 


\section{Acknowledgements}

Nil.

\section{Conflict of interest}

The authors have no conflict of interest to report.

\section{References}

[1] World Health Organization. World health statistics 2015.

https://apps.who.int/iris/bitstream/handle/10665/170250/9789240694439_eng.pdf;jsessionid=8A67ADA279AB1E2D4FAAC8E279D303DF? sequence=1. Last Updated 2015. Accessed on April 24, 2019.

[2] Prince MJ, Wu F, Guo Y, Robledo LMG, O'Donnell M, Sullivan R, et al. The burden of disease in older people and implications for health policy and practice. Lancet. 2015; doi:10.1016/S0140-6736(14)61347-7

[3] Livingston G, Sommerlad A, Orgeta V, Costafreda SG, Huntley J, Ames D, et al. Dementia prevention, intervention, and care. Lancet. 2017; doi:10.1016/S0140-6736(17)31363-6

[4] Medaglia JD, Gu S, Pasqualetti F, Ashare RL, Lerman C, Kable J, et al. Cognitive control in the controllable connectome. arXiv preprint arXiv:1606.09185. 2016 Jun 29.

[5] Stern Y. What is cognitive reserve? Theory and research application of the reserve concept. J Int Neuropsychol Soc. 2002; doi:10.1017/S1355617702813248

[6] Stern Y. Cognitive reserve. Neuropsychologia. 2009; doi:10.1016/j.neuropsychologia.2009.03.004

[7] Pinto C, Tandel KY. Cognitive reserve: Concept, determinants, and promotion. J Geriatr Ment Health. 2016;3:44.

[8] Barulli D, Stern Y. Efficiency, capacity, compensation, maintenance, plasticity: emerging concepts in cognitive reserve. Trends Cogn Sci. 2013;17:502-9.

[9] Opdebeeck C, Nelis SM, Quinn C, Clare L. How does cognitive reserve impact on the relationships between mood, rumination, and cognitive function in later life? Aging Ment Health. 2015;19:705-12.

[10] Pool LR, Weuve J, Wilson RS, Bültmann U, Evans DA, De Leon CFM. Occupational cognitive requirements and late-life cognitive aging. Neurology. 2016;86:1386-92.

[11] Robertson IH. A noradrenergic theory of cognitive reserve: implications for Alzheimer's disease. Neurobiol Aging. 2013; doi:10.1016/j.neurobiolaging.2012.05.019

[12] Jenkins L, Myerson J, Joerding JA, Hale S. Converging evidence that visuospatial cognition is more age-sensitive than verbal cognition. Psychol Aging. 2000;15:157.

[13] Johnson W, Logie RH, Brockmole JR. Working memory tasks differ in factor structure across age cohorts: Implications for dedifferentiation. Intelligence. 2010;38:513-28.

[14] Suri S, Topiwala A, Filippini N, Zsoldos E, Mahmood A, Sexton CE, et al. Distinct resting-state functional connections associated with episodic and visuospatial memory in older adults. Neuroimage. 2017;159:122-30.

[15] Golomb J, de Leon MJ, Kluger A, George AE, Tarshish C, Ferris SH. Hippocampal atrophy in normal aging: an association with recent memory impairment. Arch Neurol. 1993;50:967-73.

[16] Mungas D, Harvey D, Reed BR, Jagust WJ, DeCarli C, Beckett L, et al. Longitudinal volumetric MRI change and rate of cognitive decline. Neurology. 2005;65:565-71. 
[17] Jack Jr CR, Wiste HJ, Vemuri P, Weigand SD, Senjern ML, Zeng G, et al. Brain beta-amyloid measures and magnetic resonance imaging atrophy both predict time-to-progression from mild cognitive impairment to Alzheimer's disease. Brain 2010;133:3336-48.

[18] Cholerton B, Larson EB, Quinn JF, Zabetian CP, Mata IF, Keene CD, et al. Precision medicine: clarity for the complexity of dementia. Am J Pathol. 2016; doi:10.1016/j.ajpath.2015.12.001

[19] Tuokko H, Garrett D, McDowell I, Silverberg N, Kristjansson B. Cognitive decline in high-functioning older adults: Reserve or ascertainment bias? Aging Ment Health. 2003;7:259-70.

[20] Chan SC, Chan CC, Derbie AY, Hui I, Tan DG, Pang MY, et al. Chinese calligraphy writing for augmenting attentional control and working memory of older adults at risk of mild cognitive impairment: a randomized controlled trial. J Alzheimers Dis. 2017;58:735-46.

[21] Petersen RC, Smith GE, Waring SC, Ivnik RJ, Tangalos EG, Kokmen E. Mild cognitive impairment: clinical characterization and outcome. Arch Neurol. 1999;56:303-8.

[22] Petersen RC, Morris JC. Mild cognitive impairment as a clinical entity and treatment target. Arch Neurol. 2005;62:1160-3.

[23] Smith JL, Hollinger-Smith L. Savoring, resilience, and psychological well-being in older adults. Aging Ment Health. 2015;19:192-200.

[24] Jeste DV, Savla GN, Thompson WK, Vahia IV, Glorioso DK, Martin AvS, et al. Association between older age and more successful aging: critical role of resilience and depression. Am J Psychiatry. 2013;170:188-96.

[25] Bowling A, Iliffe S. Psychological approach to successful ageing predicts future quality of life in older adults. Health Qual Life Outcomes. 2011;9:13.

[26] Gooding P, Hurst A, Johnson J, Tarrier N. Psychological resilience in young and older adults. Int J Geriatr Psychiatry. 2012;27:262-70.

[27] Martin AvS, Distelberg B, Palmer BW, Jeste DV. Development of a new multidimensional individual and interpersonal resilience measure for older adults. Aging Ment Health. 2015;19:32-45.

[28] Shen K, Zeng Y. The association between resilience and survival among Chinese elderly. Demogr Res. 2010; doi:10.4054/DemRes.2010.23.5

[29] Montross LP, Depp C, Daly J, Reichstadt J, Golshan S, Moore D, et al. Correlates of self-rated successful aging among communitydwelling older adults. Am J Geriatr Psychiatry. 2006;14:43-51.

[30] American Psychological Association. The Road to Resilience. https://www.apa.org/helpcenter/road-resilience.aspx, Last Updated 2015. Accessed on April 24, 2019.

[31] Campbell-Sills L, Cohan SL, Stein MB. Relationship of resilience to personality, coping, and psychiatric symptoms in young adults. Behav Res Ther. 2006;44:585-99.

[32] Connor KM, Davidson JR. Development of a new resilience scale: The Connor-Davidson resilience scale (CD-RISC). Depress Anxiety. 2003;18:76-82.

[33] Netuveli G, Wiggins RD, Montgomery SM, Hildon Z, Blane D. Mental health and resilience at older ages: Bouncing back after adversity in the British Household Panel Survey. J Epidemiol Community Health. 2008;62:987-91.

[34] Fankhauser S, Wagner B, Krammer S, Aeschbach M, Pepe A, Maercker A, et al. The impact of social and interpersonal resources on adjustment disorder symptoms in older age. GeroPsych (Bern). 2010;23:227-41.

[35] Davis SW, Dennis NA, Daselaar SM, Fleck MS, Cabeza R. Que PASA? The posterior-anterior shift in aging. Cereb Cortex. $2007 ; 18: 1201-9$.

[36] Martins R, Joanette Y, Monchi O. The implications of age-related neurofunctional compensatory mechanisms in executive function and language processing including the new Temporal Hypothesis for Compensation. Front Hum Neurosci. 2015;9:221.

[37] Nasreddine ZS, Phillips NA, Bédirian V, Charbonneau S, Whitehead V, Collin I, et al. The Montreal Cognitive Assessment, MoCA: a brief screening tool for mild cognitive impairment. J Am Geriatr Soc. 2005;53:695-9.

[38] Lu J, Li D, Li F, Zhou A, Wang F, Zuo X, et al. Montreal cognitive assessment in detecting cognitive impairment in Chinese elderly individuals: a population-based study. J Geriatr Psychiatry Neurol. 2011;24:184-90.

Page 9/14 
[39] Alladi S, Arnold R, Mitchell J, Nestor PJ, Hodges JR. Mild cognitive impairment: applicability of research criteria in a memory clinic and characterization of cognitive profile. Psychol Med. 2006;36:507-15.

[40] Stephan BCM, Minett T, Pagett E, Siervo M, Brayne C, McKeith IG. Diagnosing Mild Cognitive Impairment (MCI) in clinical trials: a systematic review. BMJ Open. 2013;3:e001909.

[41] Brown L, Sherbenou RJ, Johnsen SK. TONI-3, test of nonverbal intelligence: A language-free measure of cognitive ability. Austin, TX: ProEd; 1997.

[42] Fong K, Lee K, Tsang Z, Wan J, Zhang Y, Lau A. The clinical utility, reliability and validity of the Rivermead Behavioural Memory Test Third Edition (RMBT-3) in Hong Kong older adults with or without cognitive impairments. Neuropsychol Rehabil. 2019;29:144-59.

[43] Benton AL, Varney NR, Hamsher KD. Visuospatial judgment: A clinical test. Arch Neurol. 1978;

doi:10.1001/archneur.1978.00500300038006

[44] Campbell-Sills L, Stein MB. Psychometric analysis and refinement of the connor-davidson resilience scale (CD-RISC): Validation of a 10item measure of resilience. J Trauma Stress. 2007;20:1019-28.

[45] Resnick BA, Inguito PL. The Resilience Scale: Psychometric properties and clinical applicability in older adults. Arch Psychiatr Nurs. 2011;25:11-20.

[46] IBM Corp. IBM SPSS statistics for windows, version 25.0. Armonk, NY: IBM Corp; 2017.

[47] Resnick BA. Resilience in older adults. Top Geriatr Rehabil. 2014;30:155-63.

[48] Manning LK, Carr DC, Kail BL. Do higher levels of resilience buffer the deleterious impact of chronic illness on disability in later life? Gerontologist. 2014;56:514-24.

[49] MacLeod I, Bowman P, Vander Jagt C, Haile-Mariam M, Kemper K, Chamberlain A, et al. Exploiting biological priors and sequence variants enhances QTL discovery and genomic prediction of complex traits. BMC Genomics. 2016;17:144.

[50] Centre for Policy on ageing. Resilience in Older Age. http://www.cpa.org.uk/information/reviews/CPA-Rapid-Review-Resilienceandrecovery.pdf. Last Updated May 2014. Accessed on April 24, 2019.

[51] Tugade MM, Fredrickson BL. Resilient individuals use positive emotions to bounce back from negative emotional experiences. J Pers Soc Psychol. 2004;86:320.

[52] Lamond AJ, Depp CA, Allison M, Langer R, Reichstadt J, Moore DJ, et al. Measurement and predictors of resilience among communitydwelling older women. J Psychiatr Res. 2008;43:148-54.

[53] Genet JJ, Siemer M. Flexible control in processing affective and non-affective material predicts individual differences in trait resilience. Cogn Emot. 2011;25:380-8.

[54] Ploughman M, Austin MW, Murdoch M, Kearney A, Fisk JD, Godwin M, et al. Factors influencing healthy aging with multiple sclerosis: a qualitative study. Disabil Rehabil. 2012;34:26-33.

[55] Rose SE, McMahon KL, Janke AL, O’Dowd B, de Zubicaray G, Strudwick MW, et al. Diffusion indices on magnetic resonance imaging and neuropsychological performance in amnestic mild cognitive impairment. J Neurol Neurosurg Psychiatry. 2006;77:1122-8.

[56] Tranel D, Vianna E, Manzel K, Damasio H, Grabowski T. Neuroanatomical correlates of the Benton facial recognition test and judgment of line orientation test. J Clin Exp Neuropsychol. 2009;31:219-33.

[57] McCraty R, Atkinson M. Resilience training program reduces physiological and psychological stress in police officers. Glob Adv Health Med. 2012;1:44-66.

[58] Alvord MK, Zucker B, Grados JJ. Resilience Builder Program for children and adolescents: Enhancing social competence and selfregulation-A cognitive-behavioral group approach. Research Press; 2011.

\section{Tables}


Table 1. Demographic and psycho-cognitive characteristics of the two groups (healthy and MCI).

\begin{tabular}{|c|c|c|c|c|}
\hline & $\begin{array}{l}\text { Total Sample } \\
(\mathrm{N}=233)\end{array}$ & Healthy Controls $(\mathrm{n}=198)$ & $\begin{array}{l}\text { MCI } \\
(\mathrm{n}=35) \\
\text { [high resilience; low resilience] }\end{array}$ & t/ $\chi 2$ statistics \\
\hline & Mean (S.D.) & Mean (S.D.) & Mean (S.D.) & \\
\hline 1. Age & $64.90(3.79)$ & $64.59(3.70)$ & $\begin{array}{l}66.68(3.85) \\
{[66.67(3.40) ; 66.68(4.27)]}\end{array}$ & $t(223)=-3.02 * *$ \\
\hline 2. Sex (\% males) & 32.6 & 32.8 & $\begin{array}{l}31.4 \\
{[50.0 ; 15.8]}\end{array}$ & $\chi 2(2)=0.59$ \\
\hline 3. Years of Education & $12.97(4.13)$ & $13.43(3.96)$ & $\begin{array}{l}10.38(4.16) \\
{[10.70(4.11) ; 10.13(4.29)]}\end{array}$ & $\mathrm{t}(223)=4.11^{* * *}$ \\
\hline 4. TONI-3 Score & $23.62(9.05)$ & $24.77(8.81)$ & $\begin{array}{l}17.11(7.63) \\
{[19.31(6.72) ; 15.26(8.03)]}\end{array}$ & $\mathrm{t}(231)=4.83^{* * *}$ \\
\hline 5. MoCA Score & $26.61(2.50)$ & $27.37(1.64)$ & $\begin{array}{l}22.31(2.19) \\
{[22.94(1.00) ; 21.79(2.76)]}\end{array}$ & $\mathrm{t}(231)=15.93^{* * *}$ \\
\hline 6. JLO & $21.75(4.66)$ & $22.03(4.48)$ & $\begin{array}{l}20.17(5.33) \\
{[22.81(3.47) ; 17.95 * 5.68]}\end{array}$ & $\mathrm{t}(231)=2.20^{*}$ \\
\hline 7. RBMT- story recall & $7.44(3.45)$ & $7.70(3.45)$ & $\begin{array}{l}5.96(3.08) \\
{[5.44(3.36) ; 6.40(2.84)]}\end{array}$ & $t(230)=2.79 * *$ \\
\hline 8. Resilience ${ }^{\mathrm{a}}$ & $28.06(5.60)$ & $28.23(5.49)$ & $\begin{array}{l}27.09 \text { (6.18) } \\
{[32.75(2.79) ; 22.32(3.61)]}\end{array}$ & $\mathrm{t}(231)=1.12$ \\
\hline
\end{tabular}

NOTE. $* \mathrm{p}<=.05 ; * * \mathrm{p}<=.01 ; * * * \mathrm{p}<=.001$.

a measured by Connor-Davidson Resilience Scale (CD-RISC) and the cutoff score for high and low resilience was at 28. TONI-3, Test of Nonverbal Intelligence; MoCA, Montreal Cognitive Assessment; JLO, Judgment of Line Orientation; RMBT, Rivermead Behavioural Memory Test 
Table 2. Correlations between major variables with the entire sample [healthy controls; MCl].

\begin{tabular}{|c|c|c|c|c|c|c|c|}
\hline $\begin{array}{l}\text { Major } \\
\text { variables }\end{array}$ & 1 & 2 & 3 & 4 & 5 & 6 & 7 \\
\hline 1. Age & - & & & & & & \\
\hline 2. Years of & $-0.17^{* *}$ & - & & & & & \\
\hline education & {$[-0.08 ;-0.34 *]$} & & & & & & \\
\hline 3. Non-verbal & $-0.29 * * *$ & $0.37 * * *$ & - & & & & \\
\hline \multirow[t]{2}{*}{ intelligence $^{\mathrm{a}}$} & {$\left[-0.28^{* * * ;-0.03]}\right.$} & {$[0.32 * * * ;$} & & & & & \\
\hline & & $0.35 *]$ & & & & & \\
\hline \multirow[t]{3}{*}{ 4. MoCA } & $-0.25^{* * *}$ & $0.36^{* * *}$ & $0.41 * * *$ & - & & & \\
\hline & {$\left[-0.16^{*} ;-0.15\right]$} & {$\left[0.24^{* * *}\right.$} & {$\left[0.27^{* * *}\right.$} & & & & \\
\hline & & $0.30]$ & $\left.0.46^{* *}\right]$ & & & & \\
\hline \multirow[t]{3}{*}{ 5. JLO } & $-0.20^{* *}$ & $0.27^{* * *}$ & $0.52^{* * *}$ & $0.26^{* * *}$ & - & & \\
\hline & {$\left[-0.16^{*} ;-0.25\right]$} & {$[0.22 * *$} & {$\left[0.50^{* * *}\right.$} & {$[0.22 * * ; 0.25]$} & & & \\
\hline & & $\left.0.40^{*}\right]$ & $\left.0.52^{* *}\right]$ & & & & \\
\hline \multirow[t]{3}{*}{ 6. RBMT - story recall } & -0.11 & $0.15^{*}$ & $0.21 * * *$ & $0.28^{* * *}$ & 0.10 & - & \\
\hline & {$[-0.09 ;-0.01]$} & {$[0.13 ;-0.04]$} & {$[0.21 * * ;-0.10]$} & {$[0.30 * * *$} & {$[0.12 ;-0.13]$} & & \\
\hline & & & & $-0.13]$ & & & \\
\hline \multirow[t]{3}{*}{ 7. Resilience ${ }^{b}$} & 0.06 & 0.10 & $0.18^{* *}$ & $0.16^{*}$ & $0.18^{* *}$ & 0.01 & - \\
\hline & {$[0.10 ;-0.06]$} & {$[0.08 ; 0.12]$} & {$\left[0.12 ; 0.43^{* *}\right]$} & {$\left[0.10 ; 0.35^{*}\right]$} & {$[0.08$} & {$[0.04$} & \\
\hline & & & & & $\left.0.56^{* * *}\right]$ & $-0.25]$ & \\
\hline
\end{tabular}

NOTE. ${ }^{*} \mathrm{p}<=.05 ;{ }^{* *} \mathrm{p}<=.01 ;{ }^{* *} \mathrm{p}<=.001$

a measured by Test of NonVerbal Intelligence (TONI-3)

b measured by Connor-Davidson Resilience Scale (CD-RISC)

MoCA, Montreal Cognitive Assessment; JLO, Judgment of Line Orientation; RMBT, Rivermead Behavioural Memory Test

Table 3. Hierarchical logistic regression analyses in predicting $\mathrm{MCl}$. 


\begin{tabular}{|c|c|c|c|c|c|}
\hline Block & Variables & $\beta$ (S.E.) & p & $\begin{array}{l}\text { Odds ratio } \\
(95 \% \mathrm{CI})\end{array}$ & $\mathbf{R}^{2}$ \\
\hline 1 & Age & $0.14(0.05)$ & .004 & $1.14(1.04-1.26)$ & 0.062 \\
\hline \multirow[t]{5}{*}{2} & Age & $0.08(0.05)$ & .119 & $1.08(0.98-1.20)$ & \\
\hline & Years of education & $-0.15(0.06)$ & .015 & 0.86 (0.76- 0.97) & \\
\hline & TONI-3 & $-0.08(0.03)$ & .006 & $0.92(0.87-0.98)$ & \\
\hline & JLO & $0.03(0.05)$ & .521 & $1.03(0.94-1.13)$ & 0.259 \\
\hline & RBMT - story recall & $-0.13(0.07)$ & .062 & $0.88(0.77-1.01)$ & \\
\hline \multirow[t]{6}{*}{3} & Age & $0.08(0.05)$ & .108 & 1.09 (0.98- 1.21) & \\
\hline & Years of education & $-0.15(0.06)$ & .014 & $0.86(0.76-0.97)$ & \\
\hline & TONI-3 & $-0.08(0.03)$ & .008 & $0.92(0.87-0.98)$ & \\
\hline & JLO & $0.04(0.05)$ & .471 & $1.04(0.94-1.14)$ & \\
\hline & RBMT - story recall & $-0.13(0.07)$ & .061 & $0.88(0.77-1.01)$ & \\
\hline & Resilience & $-0.02(0.04)$ & .625 & $0.98(0.92-1.05)$ & 0.261 \\
\hline \multirow[t]{7}{*}{4} & Age & $0.05(0.06)$ & .356 & $1.05(0.94-1.17)$ & \\
\hline & Years of education & $-0.14(0.07)$ & .035 & 0.87 (0.77- 0.99) & \\
\hline & TONI-3 & $-0.09(0.03)$ & .004 & 0.91 (0.86- 0.97) & \\
\hline & JLO & $-0.44(0.23)$ & .051 & $0.64(0.41-1.00)$ & \\
\hline & RBMT - story recall & $-0.15(0.07)$ & .045 & $0.86(0.75-1.00)$ & \\
\hline & Resilience & $-0.38(0.17)$ & .028 & $0.68(0.49-0.96)$ & \\
\hline & resilience x JLO & $0.02(0.01)$ & .030 & $1.02(1.00-1.04)$ & 0.295 \\
\hline
\end{tabular}

NOTE. $C I=$ Confidence Intervals; $\mathrm{R}^{2}=$ Nagelkerke R Square for each block; Significance values $<=.05$ were in bold. TONI-

3, Test of NonVerbal Intelligence; JLO, Judgment of Line Orientation; RBMT, Rivermead Memory Test

\section{Figures}




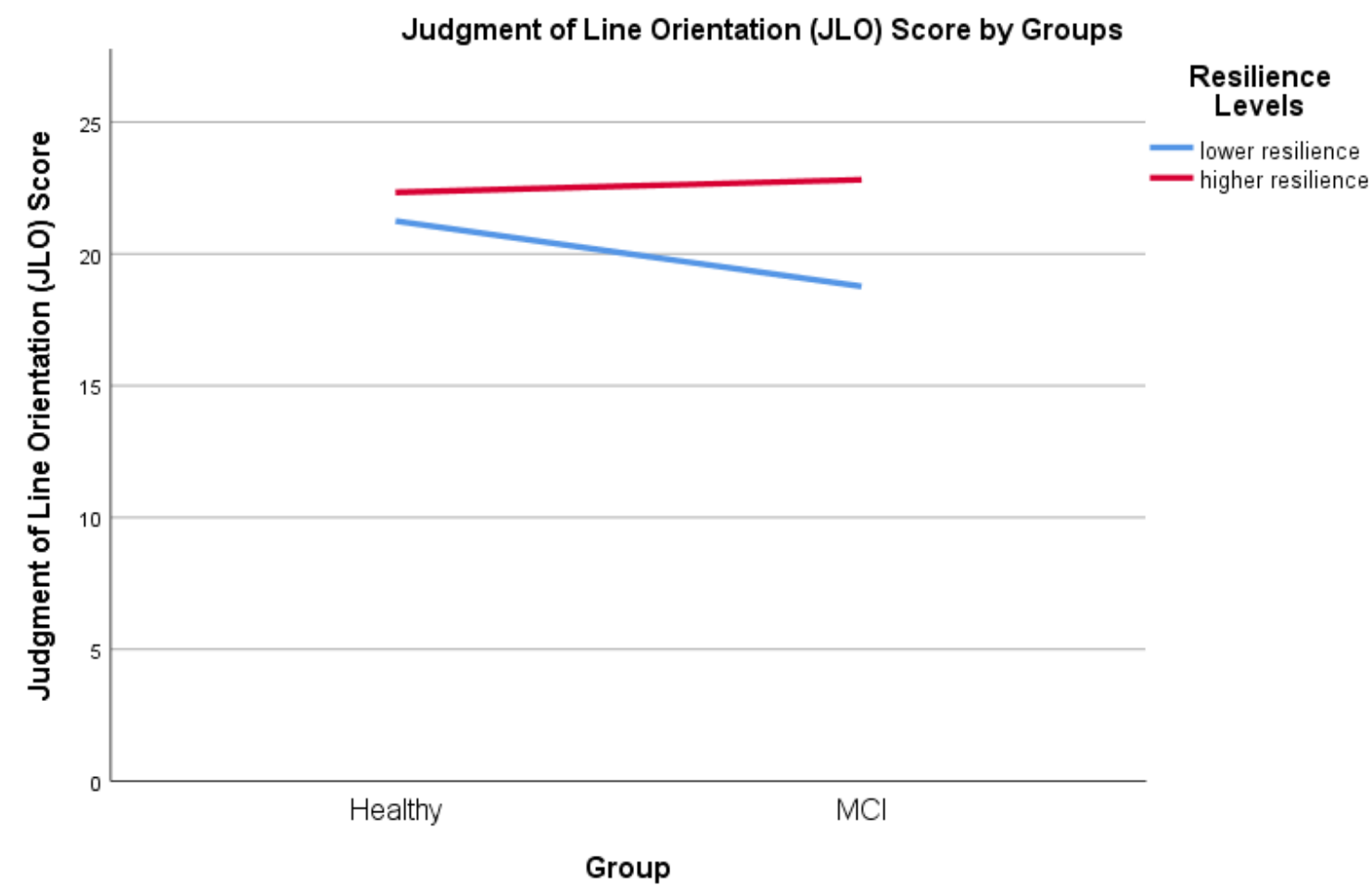

Figure 1

The interaction effect of JLO scores and resilience levels on 2 Groups. To test the moderation effect of visuospatial ability in predicting MCI at different levels of resili-ence, all participants were split into two resilience groups based on the median score at 28 on CD-RISC: lower resilience (CD-RISC score $<=28)(n=114)$ and higher resilience group (CD-RISC score $>28)(n=119)$. Within the healthy controls, there were 103 and 95 participants in higher resilience and lower resilience respectively while there were 16 higher resilience and 19 lower resilience individuals among those with $\mathrm{MCl}$. 